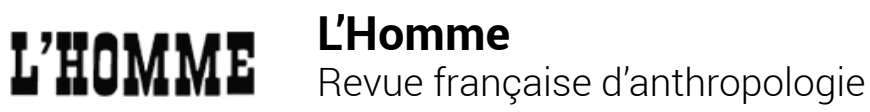

177-178 | 2006

Chanter, musiquer, écouter

\section{Richard Bauman, A World of Others' Words. Cross- Cultural Perspectives on Intertextuality} Malden-Oxford, Blackwell Publishing, 2004, 182 p., bibl., index

Jean-Louis Siran

\section{OpenEdition}

\section{Journals}

Édition électronique

URL : http://journals.openedition.org//homme/2300

DOI : 10.4000/lhomme.2300

ISSN : 1953-8103

Éditeur

Éditions de l'EHESS

Édition imprimée

Date de publication : 1 juin 2006

Pagination : 526-527

ISSN : 0439-4216

Référence électronique

Jean-Louis Siran, «Richard Bauman, A World of Others' Words. Cross-Cultural Perspectives on Intertextuality », L'Homme [En ligne], 177-178 | 2006, mis en ligne le 12 avril 2006, consulté le 24 septembre 2020. URL : http://journals.openedition.org//homme/2300 ; DOI : https://doi.org/10.4000/ Ihomme.2300

Ce document a été généré automatiquement le 24 septembre 2020.

(c) École des hautes études en sciences sociales 


\title{
Richard Bauman, A World of Others' Words. Cross-Cultural Perspectives on Intertextuality
}

Malden-Oxford, Blackwell Publishing, 2004, 182 p., bibl., index

\author{
Jean-Louis Siran
}

1 CERTES, IL EST des chercheurs en France qui se déclarent folkloristes mais, ce faisant, et quelle que soit l'estime dont ils peuvent être l'objet, ils savent qu'ils se désignent par là même d'un titre peu valorisant. Quiconque s'intéresse ici aux contes, par exemple, ou à toute autre sorte d'énoncé oral pour en proposer l'analyse en un langage de quelque ambition se déclarera d'emblée anthropologue. Cela ne semble pas être le cas aux ÉtatsUnis. Il s'y trouve sans doute bien des chercheurs attachés à repérer dans tel récit enregistré en Oregon ou en Oklahoma telle ou telle variante de tel ou tel conte-type tel que repéré et numéroté par les Finlandais, mais une revue comme le Journal of American Folklore a depuis longtemps dépassé ces soucis d'entomologiste. C'est aussi que l'étude des «textes" (avec tous les guillemets dont il convient d'entourer un terme aussi problématique) y a été bien autrement problématisée qu'en Europe, et qu'elle y a été menée avec un sérieux et un respect dont les structuralistes de chez nous (derniers hussards du ce-qu'-il-en-est-en-dernière-instance) ne se sont jamais encombrés. Ledit journal aura été, et continue d'être au carrefour d'interrogations plurielles et amicalement convergentes : l'ethnographie de la communication (Hymes), la poétique de l'énoncé (Tedlock), la sociologie de l'interlocution (Sherzer) ou l'analyse de l'«art verbal » (Bauman).

2 Richard Bauman publie aujourd'hui un ouvrage qui n'est qu'un recueil d'articles, mais dont il a su, après-coup, organiser la cohérence et montrer en quoi chacun d'eux s'éclaire de tous les autres. La perspective centrale étant que la vie sociale s'organise autour d'actes de langage qui sont à la fois ancrés dans le contexte situationnel, et transcendants parce que liés de manière interdiscursive à d'autres situations, d'autres énonciations. Il n'est certes pas possible de maintenir la conception qui pouvait être celle de Herder ou de Boas (Bauman dixit) selon laquelle les textes sont des objets dotés 
d'une existence autonome et liés les uns aux autres par une relation de filiation. Il convient donc plutôt de concevoir les textes comme des moments (d'« entextualisation») dans un processus incessant de décontextualisation/ recontextualisation.

3 Le texte est un discours produit ici et maintenant, dans son contexte d'émergence mais objectivé, doté d'une cohérence interne qui le constitue comme objet extrait (ou plutôt extractable) de son contexte de production, ce qui lui permet de circuler, d'être spoken again dans un autre contexte qui lui donnera, en un nouvel ici et maintenant, de nouveaux liens dans un nouvel environnement discursif. Il n'est donc de « texte » que dans une dialectique (terme que n'emploie pas Bauman) de la production/réception, dans une intertextualité qui se tisse (se tisse et se détisse) dans les différentes situations, et sous toutes sortes d'enjeux sociaux dont Bauman analyse ici (je rappelle qu'il s'agit d'un recueil d'articles) toute une collection : cris d'appel des vendeurs sur un marché mexicain, histoires drôles d'un pêcheur du Texas, anecdotes vécues ou rapportées d'un îlien de Nouvelle-Écosse, légendes islandaises. Le plus intéressant étant à mes yeux le dernier, "Mediation, Tradition, Authority", où deux figures du médiateur sont mises en perspective : l'aède fidjien d'une part, dont on louera le talent de performer, mais qui est pensé n'être que le récitant (devant l'auditoire actuel) d'un texte dont il aurait lui-même été tout d'abord l'auditeur (le texte lui étant dicté en rêve par un ancêtre); le porte-parole d'autre part, le spokesman du chef akan, qui répète à l'instant même les paroles prononcées par le chef, tantôt telles quelles, tantôt largement développées, fleuries, ornées et enrichies (Bauman s'appuie ici sur les travaux de Kwesi Yankah). 